Corps et culture

Numéro 3 | 1998

Sport et lien social

\title{
Sport et lien social
}

\section{Yves Le Pogam}

\section{(2) OpenEdition}

Journals

Édition électronique

URL : http://journals.openedition.org/corpsetculture/409

DOI : 10.4000/corpsetculture.409

ISSN : $1777-5337$

\section{Éditeur}

Association Corps et Culture

Édition imprimée

Date de publication : 1 juin 1998

ISSN : 1268-5631

\section{Référence électronique}

Yves Le Pogam, "Sport et lien social », Corps et culture [En ligne], Numéro 3 | 1998, mis en ligne le 04 mai 2007, consulté le 22 septembre 2020. URL : http://journals.openedition.org/corpsetculture/409 DOI : https://doi.org/10.4000/corpsetculture.409

Ce document a été généré automatiquement le 22 septembre 2020

(c) tous droits réservés 


\title{
Sport et lien social
}

\author{
Yves Le Pogam
}

1 En prenant comme objet pour nos séminaires annuels de laboratoire le thème «Sport et lien social », les membres de "Corps et Culture » avaient conscience d'entrer dans une problématique très contextualisée. La société était traversée par un désordre caractérisé par des fragmentations sociales entre le travail et le non travail, par les violences urbaines, les grèves, les revendications des chômeurs et des sans papiers, par des conflits communautaires et les idéologies extrémistes à l'égard de l'étranger. Une anomie bien analysée par l'anthropo-sociologie comme en témoignent les nombreux ouvrages s'attachant à comprendre l'exclusion, le racisme, la perte du lien social tout en soulignant la puissance du social à le recomposer. Le lien social, pris dans le mouvement de sa défection et de sa réfection devient alors un analyseur anthropologique de la modernité. La perte du lien suscite des reprises d'initiatives pour repolariser le socius ce qui atteste de la dynamique d'une société en création continue. Parmi toutes les actions permettant de lutter contre la déperdition du lien, le sport apparaît idéologiquement comme une pratique intégrative permettant de panser les plaies de la société répercutées notamment dans les banlieues. Les actions, encouragées par le politique, appuyées par de nombreuses recherches ou observations, se sont multipliées pour pallier au désordre dans l'espoir de créer des liens en partant du postulat selon lequel les rapports à l'autre dans le sport, initiés par l'apprentissage et par l'obéissance aux règles d'une pratique légitimée socialement, sont transférables dans les conduites de la vie quotidienne.

2 Ce n'est pas uniquement cette logique fondée sur les vertus intégratives du sport qui a été à l'origine de notre questionnement. De nombreuses publications mentionnaient déjà les initiatives prises en la matière. Nous souhaitions en outre montrer l'ambiguïté de l'idée de « reliance » rapportée au sport. Les travaux anthropo-sociologiques guidés par des épistémologies contrastées nous alertent sur cette question. Qu'y a-t-il de commun par exemple entre une approche phénoménologique et une vue critique du sport pour penser le lien social?

3 Le regard phénoménologique maximise dans le sport la part du sensible, ce qui nous touche, l'émotion ressentie et partagée par la pratique ou lors d'un spectacle, les rituels 
qui mettent en relation le sujet avec la collectivité. Par le sport, le sujet échappe au narcissisme en étant obligé de composer avec l'autre, les groupes ou les communautés trouvent là un vecteur d'identification et les États-nations peuvent communiquer lors de grands événements internationaux sur un mode apparemment plus neutre, voire même renouer des relations diplomatiques grâce au sport. La socialité ainsi révélée se détache de toutes les emprises économiques et politiques, une vue que la perspective critique va au contraire prendre en compte. Ici le soupçon sur les facultés liantes du sport guide les analyses. Est-il réaliste de penser un sport autonome, coupé de la société dans laquelle il s'enracine? Les valeurs de rationalité, de productivité, d'échanges marchands au fondement du sport et de la société entraînent une logique d'exclusion, de hiérarchisation qui segmente plus qu'elle ne lie. Ne faut-il pas souligner aussi la fragilité des relations interpersonnelles nouées dans les gymnases, les salles de sport ou dans les sports d'aventure où souvent les autres ne valent que parce qu'ils renforcent le souci de soi ? Que dire aussi du détournement par le Capital sportif des liens qui font la culture populaire des jeunes des townships de l'Afrique du Sud ou des favellas brésiliennes, repérés par des réseaux puis vendus très jeunes aux clubs des pays riches qui espèrent en faire des champions afin que leur investissement fructifie? Ces quelques exemples mettent en question les vertus fédératrices du sport.

4 Le sport révèle un lien social condensant cette double polarité : il génère une socialité par l'émotion, les fusions, les élans affectifs et se structure sur des réseaux construits sur la recherche du profit économique ou politique. Certes il présente des analogies avec la religion en étant fondé sur une culture qui relie, mais cette culture se laïcise sous l'emprise des institutions, de la rationalité et des intérêts marchands.

C'est à un essai de compréhension de cette complexité auquel est consacré ce numéro dont les analyses partent soit de données empiriques permettant de voir quelques formes du lien social en acte dans le sport, soit de données théoriques se rapportant au lien, saisies dans leurs différences. Les lieux d'investigation et les populations interrogées sont variés: communautés de jeunes pratiquants les sports de rue, conduites juvéniles à risque, aventuriers de Raids, homosexuels en quête d'identification, handicapés s'intégrant par le sport, institutions sportives dont la restructuration perturbe les liens existants, pratiques traditionnelles se transformant en générant de nouveaux liens.

6 Ce numéro, comme les précédents, est structuré en quatre rubriques.

7 La première partie, «Thématiques ", présente quelques formes du lien articulées en trois directions.

Dans la première, « Mythologies sportives et liens transgressifs ", les modes de socialité dans le sport sont interrogés dans leurs composantes imaginaire et mythique notamment dans la séparation qui s'institue entre l'idéologie du sport institutionnalisé et les formes transgressives saisissables dans la multiplicité des communautés sportives qui émergent. Dans ce sens, Nancy Midol s'attache à comprendre les mythes qui structurent le sport et le corps de la modernité et montre comment la marchandisation, la normalisation, le management qui la caractérisent, questionnent le lien social en produisant des projets (hors limite, orientalisation du corps, etc.), caractérisés davantage par la recherche de la jouissance que par une volonté de révolte. C'est le dévoilement de quelques paradoxes relatifs au lien qui intéresse Betty Lefèvre, car le sport simultanément distingue et relie. En s'appuyant sur les théories de Michel Maffesoli, elle montre comment naissent, contre la rationalité, des tribus ou des 
communautés de rue se distanciant du sport institutionnalisé par leurs manières de faire et par leurs imaginaires. C'est à partir d'un événement sportif, associant l'aventure et la fête que Gisèle Lacroix montre comment l'organisation formelle d'une manifestation génère des modes de sociabilité fondés sur les liens émotionnels, sur une ambiance très écologique, sur la concurrence des groupes, sur le défi, agrégeant les pratiquants en un être-ensemble dont les formes varient pendant la durée de la course.

Dans la seconde direction, «Liens sportifs et différenciations identitaires » les auteurs interrogent trois populations différentes liées à des institutions sportives. Ainsi, Nathalie Lefèvre analyse l'appropriation du sport par le mouvement gai et lesbien lors des Eurogames qui se sont déroulés à Paris en juin 1997. Elle montre que les associations sportives homosexuelles permettent l'affirmation identitaire de cette communauté. Mais cette communauté n'est pas unifiée et des divisions se manifestent entre ceux qui plaident pour l'autonomie de leur mouvement et ceux qui, tout en appartenant aux clubs gais ou lesbiens souhaitent intégrer la logique sportive fédérale. C'est une autre population qu'interrogent Odile Deleuze et Gilles Bui-Xuân. Ils analysent le rôle d'un sport collectif officiel, le torball, et les transformations identitaires qu'il permet chez les sujets déficients visuels. Ils montrent que la ségrégation liée au handicap se transforme en intégration grâce au niveau sportif auquel ils sont parvenus, équivalant à celui des pratiquants sportifs ordinaires. Enfin, Jean-Bernard Moles saisit les métamorphoses du lien social à partir du procès de professionnalisation que connaît le rugby actuellement. Il montre la distension des liens intra-organisationnels générés par la multiplication des groupes formels en conflit pour la défense de leurs intérêts. Une nouvelle culture rugbystique émerge, construite sur la déstructuration des anciens liens et sur la construction de nouvelles divisions séparant l'élite de la masse.

Dans un troisième temps, "Lien social et conduites juvéniles », les contributions se concentrent sur des thèmes très actuels comme le risque et la violence dans la jeunesse. Bastien Soulé et Jean Corneloup témoignent de l'intérêt pour les conduites à risques comme catalyseur du lien, et en s'appuyant sur le cadre théorique de l'expérience et sur une comparaison entre deux groupes (des jeunes bien intégrés et instables), soulignent ce qui à la fois est vécu de manière différentielle et ce que ces groupes hétérogènes ont en commun. La notion de risque ne renvoie pas à une vue unifiée. La question du lien social et de la jeunesse est également évoquée par Marc Barthélémy à partir d'une institution, l'école. La violence est actuellement l'objet d'une attention soutenue ainsi que l'idée de citoyenneté, idée que l'école doit promouvoir comme réponse à cette crise du lien. Il analyse les contradictions à la réalisation de cette expérience citoyenne.

11 La deuxième rubrique " Critiques " questionne la manière dont le lien social peut être conçu dans le sport. Jacques Gleyse montre que le lien social est l'objet d'analyses contradictoires et propose une réflexion sur la nature de ce lien à partir de l'agir communicationnel de Jürgen Habermas, l'argent, le langage et le pouvoir. Il aboutit au fait que le sport relie dans une perspective du marché, moins dans celle de la citoyenneté. Puis Mahmoud Miliani entreprend une analyse comparative entre trois sociologies, Jean-Marie Brohm, Michel Maffesoli et Pierrre Sansot. En se référant aux travaux de Luc Boltanski et de Laurent Thévenot, il considère les points de vue des auteurs relativement au lien social, non pas comme des visions du monde mais comme la construction d'un monde dont il précise les contours. C'est aussi à une analyse 
épistémologique du lien social mise en relation avec une pratique traditionnelle comme les joutes à laquelle se livrent Charles Pigeassou et Jérôme Pruneau. Leur objectif est de montrer comment les paradigmes sociologiques qui caractérisent le lien social peuvent éclairer les différentes formes du lien et les transformations que subit cette pratique traditionnelle en mutation.

La troisième partie « Un auteur » est consacrée cette fois à Michel Maffesoli dont les travaux depuis plus d'une vingtaine d'années cherchent, par de multiples approches complémentaires, à révéler les formes (re)naissantes de la socialité. Michel Maffesoli est Professeur à la Sorbonne, directeur du C.E.A.Q. (Centre d'Étude sur l'Actuel et le Quotidien) composé de neuf groupes de recherches qui présentent chaque année le résultat de leurs travaux en juin. Michel Maffesoli est en outre responsable de rédaction de la revue Sociétés et a organisé de nombreux colloques en collaboration avec le C.R.I. (Centre de Recherche sur l'Imaginaire) auquel est attaché le nom de Gilbert Durand. Il entretient des relations étroites avec le G.R.I.M.I. (Groupe de Recherches sur l'Imaginaire de Montpellier Interdisciplinaire) et l'I.R.S.A. (Institut de Recherches Sociologiques et Anthropologiques, responsable Jean-Marie Brohm). Ses publications sont nombreuses, une douzaine d'ouvrages, d'autres réalisés en collaboration, des préfaces et plus d'une centaine d'articles en langue française, sans compter les publications en langues étrangères. Les travaux de Michel Maffesoli pénètrent les S.T.A.P.S. dès les années 80 , en même temps que ceux de Pierre Bourdieu. Il a publié dans les revues proches du champ comme Quel Corps et Science et Motricité affirmant par là son intérêt pour les problématiques corporelles et sportives dont la présence s'affirme à plusieurs reprises dans ses ouvrages. Il a répondu à notre demande en nous confiant un article "Société et communauté. Tribalisme et sentiment d'appartenance » dans lequel il précise comment la culture est liée à l'esprit du temps et nous façonne. L'épistémè qui caractérise une époque n'est pas fixée définitivement. Elle se sature et génère d'autres formes culturelles. Ce sont ces transformations, difficiles à repérer, que s'efforce de saisir Michel Maffesoli dans le passage de la modernité rationaliste, individualiste et finalisée à la postmodernité dont il s'attache à montrer le sensualisme perceptible dans le tribalisme où les liens émotionnels sont prévalents. Ceci est généré par la saturation du politique, du rôle des institutions des grands récits de référence, de l'identité qui laisse la place à de multiples identifications. Sont exposées là quelques grandes directions qui jalonnent l'oeuvre de Michel Maffesoli consacrée à l'émergence des manières d'être-ensemble et aux nouvelles formes de socialité. C'est cette direction que tente d'approcher Yves Le Pogam à partir de la lecture des ouvrages de Michel Maffesoli dans l'objectif de montrer la singularité d'une pensée, l'épistémologie qui la guide et les multiples formes qu'elle dévoile par la diversité des objets explorés. Une pensée qui ouvre à une compréhension de la pulsion d'être-ensemble présente dans le banal de la vie quotidienne, un objet doté alors d'une richesse insoupçonnée.

13 Cet avant-propos se poursuit par un article de Mahmoud Miliani qui analyse quelques événements survenus au moment où notre du laboratoire se questionnait sur le lien social, événements marqués par une problématique du lien située à trois niveaux : celui de la société, celui de notre établissement, la Faculté des Sciences du Sport de Montpellier, et celui de notre propre structure de recherche, l'équipe «Corps et Culture ». 


\section{AUTEUR}

\section{YVES LE POGAM}

Faculté des Sciences du Sport et de l'Education Physique. Université Montpellier 1. Equipe «Corps et Culture» 